DOI: $10.5902 / 1984686 \times 27314$

\title{
Narrativas de professores e pedagogos sobre a deficiência: implicações no acesso ao currículo escolar
}

Narratives of teachers and pedagogues on disability: implications for access to the school curriculum

Narrativa de profesores y pedagogos sobre la discapacidad: implicaciones en el acceso al currículo escolar

* Alexandro Braga Vieira

Doutor na Universidade Federal do Espírito Santo, Vitória, Espirito Santo, Brasil. allexbraga@hotmail.com

** Ines de Oliveira Ramos

Doutora pela Universidade Federal do Espírito Santo, Vitória, Espirito Santo, Brasil. inesram.ufes@gmail.com

*** Renata Duarte Simões

Doutora pela Universidade Federal do Espírito Santo, Vitória, Espirito Santo, Brasil.

renasimoes@hotmail.com

Recebido: 2 de maio de 2018

Aprovado: 15 de outubro de 2018

\section{RESUMO}

As narrativas de professores e pedagogos têm indicado pistas para compreensão sobre a maneira como os alunos com deficiência vêm sendo significados e como essa significação tem produzido barreiras para o acesso ao currículo escolar. A reflexão crítica dessas narrativas tem apontado possibilidades para os professores reverem seus posicionamentos sobre a escolarização dos alunos, potencializando os saberes-fazeres docentes e as práticas pedagógicas. Objetivou-se, problematizar a maneira como os profissionais da educação vêm significando os modos de ser/estar de estudantes com deficiência na escola, o que traz implicações no acesso ao conhecimento. Constitui uma pesquisa de campo, realizada em uma escola de ensino fundamental de Vila Velha-ES, pautada nos pressupostos da pesquisa-ação colaborativo-crítica. $O$ processo de pesquisa se organizou por meio de quatro frentes de trabalho: a) observação do cotidiano escolar para capturar as narrativas dos professores; b) organização de momentos de formação continuada para a reflexão crítica dessas narrativas; c) ações de colaboração entre pesquisadores e professores em sala de aula; d) realização de entrevistas com os sujeitos envolvidos. Concluiu que, no interior da escola, as relações que se estabelecem na sociedade também são reproduzidas, reafirmando os processos de exclusão de sujeitos que não se adaptam aos padrões de comportamento considerados normais. Em contrapartida, o debate crítico sobre as narrativas dos professores e o investimento na formação continuada podem 
DOI: $10.5902 / 1984686 \times 27314$

contribuir para a superação de práticas excludentes e para a ressignificação dos alunos com deficiência, favorecendo a aprendizagem e o envolvimento nos currículos escolares. Palavras-chave: Educação Especial; Currículo; Formação Continuada.

\section{ABSTRACT}

Teachers and pedagogues' narratives have indicated clues to understanding about how students with deficiency have been means and how theses meanings are producing barriers to accessing the school curriculum. The critical reflection of these narratives has pointed possibilities for the teachers to review their positions on the schooling of students, potentializing teachers' know-how and pedagogical practices. The objective of this study was to problematize the way in which the teachers of education have been signifying the ways of being/being of students with the deficiency in the regular school, which has implications in the access to the knowledge. This study was constituted as a field research, carried out in a primary school of Vila Velha-ES, based on the presuppositions of collaborative-critical action research. The research process is organized through four fronts of work: a) observation of school daily to capture as teachers' narratives; b) organization of moments of continuous formation for critical reflection of narrative; $c$ ) collaborative actions between researchers and teachers in the classroom; d) interviews with the subjects involved. It concluded that, within the school, relationships that are found in society are also reproduced, reaffirming the processes of exclusion of subjects that do not conform to normal behavior patterns. On the other hand, the critical debate about teachers' narratives and the investment in continuing formation can contribute to overcoming exclusionary practices and to the re-signification of students with deficiency, favoring learning and involvement in school curricula.

Keywords: Special Education; Curriculum; Continuing Education.

\section{RESUMEN}

Las narrativas de profesores y pedagogos han indicado pistas para la comprensión sobre la manera como los alumnos con deficiencia vienen siendo significados y como esa significación ha producido barreras para el acceso al currículo escolar. La reflexión crítica de esas narrativas han apuntado posibilidades para que los profesores revean sus posicionamientos sobre la escolarización de los alumnos, potencializando los sabereshaceres docentes y las prácticas pedagógicas. Se objetivó, con este estudio, problematizar la manera como los profesionales de educación vienen significando los modos de ser/estar de estudiantes con deficiencia en la escuela regular, lo que trae implicaciones en el acceso al conocimiento. Este estudio constituye una pesquisa de campo, realizada en una escuela de educación primaria de Vila Velha-ES, pautada en los supuestos de la pesquisa-acción colaborativo-crítica. El proceso de pesquisa se organizó por medio de cuatro frentes de trabajo: a) observación del cotidiano escolar para capturar las narrativas de los profesores; b) organización de momentos de formación continuada para la reflexión crítica de esas narrativas; c) acciones de colaboración entre investigadores y profesores en el salón de clases; d) realización de entrevistas con los sujetos involucrados. Concluyose que, en el 
DOI: $10.5902 / 1984686 \times 27314$

interior de la escuela, las relaciones que se establecen en la sociedad también son reproducidas, reafirmando los procesos de exclusión de sujetos que no se adaptan a los padrones de comportamiento considerados normales. En contrapartida, el debate crítico sobre las narrativas de los profesores y la inversión en la formación continuada pueden contribuir para la superación de prácticas excluyentes y para la resignificación de los alumnos con deficiencia, favoreciendo el aprendizaje y el envolvimiento en los currículos escolares.

Palabras clave: Educación Especial; Currículo; Formación Continuada.

\section{Introdução}

No contexto atual, temos direcionado atenções para os cotidianos educacionais visando lançar uma escuta sensível (BARBIER, 2004) sobre as narrativas produzidas por professores e pedagogos acerca dos modos de ser/estar de estudantes com deficiência que vivenciam processos de inclusão escolar. Essas narrativas, em muitas situações, fazem correlações entre a deficiência e a impossibilidade de a pessoa com algum tipo de limitação poder aprender, conjugando a diferença aos pressupostos da desigualdade e da exclusão social/escolar, dificultando o acesso ao conhecimento sistematizado. A existência desse cenário nos motiva a produzir este texto, que objetiva problematizar a ideia de que a maneira como os profissionais da educação significam os modos de ser/estar de estudantes com deficiência na escola regular acaba por causar dificuldades para que eles acessem o conhecimento.

Este estudo constitui uma pesquisa de campo, realizada em uma escola de ensino fundamental de Vila Velha-ES, pautada nos pressupostos da pesquisa-ação colaborativocrítica. Como participantes, tivemos o diretor escolar, duas pedagogas, duas coordenadoras de turnos e 22 professores. Para este artigo, realizamos um recorte e optamos por trazer somente as narrativas proferidas pelos professores. Por meio da observação do cotidiano escolar, as narrativas eram armazenadas em diários de campo e em videogravações para serem discutidas nos momentos de formação em contexto. Paralelamente a essa fase, constituímos quatro momentos de formação que duraram, cada um deles, duas horas e meia, com base em discussões que abordavam os modos como os professores significavam o processo de inclusão dos alunos na escola; as redes de apoio à escolarização desses sujeitos; a formação inicial e continuada dos professores; e a articulação entre o currículo e o trabalho pedagógico realizado na sala de aula comum. 


\section{DOI: $10.5902 / 1984686 \times 27314$}

Essas formações estavam previstas no calendário escolar, das quais duas foram realizadas no primeiro semestre e as outras duas no segundo semestre de 2012. As narrativas também foram coletadas nos momentos de trabalho colaborativo em sala de aula comum.

Além disso, para complementar algumas questões, foram feitas entrevistas semiestruturadas, focando os mesmos eixos que conduziram os espaços-tempos de formação em contexto. A escola ofertava matrícula para estudantes do 1. ao 6. ano do ensino fundamental, constituindo um quadro de 510 discentes. Dentre esses, havia a presença de 21 alunos com deficiência. Os dados foram coletados em um período de um ano (2012), cuja investigação foi realizada na escola, três vezes por semana. Para a fundamentação teórica deste texto, recorremos às contribuições de Santos (2006, 2007, 2008) e de autores do campo da Educação Especial.

\section{Um olhar sobre a sociedade e a escola com base no paradigma moderno}

Santos (2006, 2007), ao produzir análises críticas sobre a conjuntura social contemporânea, aponta-nos um conjunto de pistas para entendermos o desenrolar dos processos de exclusão na sociedade e, consequentemente, nas escolas. Para esse autor, o pensamento moderno vem produzindo uma sociedade dividida por linhas abissais, ou seja, uma sociedade repartida. De um lado, convivem as realidades visíveis e, de outro, as invisíveis. Na parte visível, estão todos os conhecimentos, experiências e modos de existências valorados pela racionalidade moderna (a ciência), enquanto, na invisível, é depositado o que precisa ser descartado, porque é considerado estéril.

A escola, fazendo parte dessa conjuntura social, acaba por organizar o trabalho pedagógico embasada em linhas abissais também presentes na sociedade repartida em que vivemos. Em sala de aula, há aqueles estudantes que têm seus modos de ser aluno valorados, pois dão "respostas" aos professores com base no que foi previamente planejado, os quais convivem no lado visível das linhas abissais. Em contrapartida, no lado invisível, são lançados aqueles que possuem modos diferenciados de se relacionarem com os conhecimentos - pessoas que vivenciam o que vem sendo denominado de "fracasso escolar".

Ao analisar a constituição dessa sociedade repartida por linhas abissais, Santos (2007) problematiza como os pressupostos da desigualdade e da exclusão vão se desenhando. Para ele, tanto a desigualdade quanto a exclusão são dois sistemas de pertença hierarquizados: o primeiro é um fenômeno socioeconômico; o segundo, um 
DOI: $10.5902 / 1984686 \times 27314$

fenômeno cultural e social. A desigualdade implica um sistema hierárquico de integração social que leva determinados grupos sociais a conviver em sociedade, no entanto de maneira desigual, tendo em vista não terem posse de capital econômico e social para uma vida mais equânime. Já a exclusão social é "[...] um processo histórico através do qual uma cultura, por via de um discurso de verdade, cria o interdito e o rejeita" (SANTOS, 2006, p. 281).

Tudo isso chega às escolas e implica os modos como os conhecimentos são mediados em sala de aula e os alunos subjetivados. As escolas se comprometem em apresentar aos alunos conhecimentos retirados de determinados estoques da cultura que pouco ajudam os estudantes a interpretar, de maneira crítica, a sociedade em que vivem; delimitam tempos para trabalhar os conteúdos e para os alunos deles se apropriarem; exploram o trabalho pedagógico como se todos os estudantes tivessem as mesmas trajetórias de vida e de aprendizagem; descartam os conhecimentos e experiências locais; e mensuram o que foi apresentado aos estudantes, para aferir quanto de conhecimento se apropriaram.

Muitos são os obstáculos no processo de inclusão, um dos quais é o modo como as pessoas se relacionam com a diferença e significam a deficiência. Em vários casos, a deficiência é permeada por um conjunto de imagens que guiam sentimentos de estranheza, medo e hostilidade. Essa condição afeta as relações entre as pessoas, seja no campo intelectual, no racional, no relacional, no emocional e/ou no afetivo, gerando, assim, imagens e informações impróprias, disposições psíquicas ou afetivas em relação à pessoa que apresenta algum tipo de comprometimento.

Esse conjunto de imagens constituídas sobre a deficiência tem levado professores a produzir narrativas sobre os modos de ser/estar de estudantes apoiados pela Educação Especial que vivenciam processos de inclusão na escola de ensino regular. Essas narrativas vêm sempre carregadas de "nãos": não falam; não simbolizam; não dão feedback ao professor; não acompanham a turma; não apresentam possibilidades de aprendizagem; não se locomovem, entre outros muitos "nãos" que podíamos aqui elencar.

Com base nas demandas investigativas aqui expostas, cabe questionar: o que narram os professores sobre os modos de ser/estar dos alunos com deficiências na escola regular? Essas narrativas podem fundamentar momentos de formação em contexto com os profissionais da Educação? Esse último questionamento aponta a possibilidade de organizarmos momentos de formação com base nas questões vividas nas escolas em 
DOI: $10.5902 / 1984686 \times 27314$

articulação com questões teóricas, possibilitando aos professores criar outras linhas de análise e de ação, apoiados na reflexão crítica de como pensam e organizam o trabalho pedagógico com os alunos público-alvo da Educação Especial.

\section{O que narram os professores sobre os processos de inclusão de alunos com deficiência nas escolas regulares?}

Ao analisarmos as narrativas produzidas por professores sobre o processo de escolarização de alunos com deficiência na escola de ensino regular, um primeiro destaque diz respeito a uma relação de dependência para com os laudos médicos. $A$ incorporação dos laudos nas narrativas dos professores parece querer justificar certo sentimento de não saber o que fazer com o aluno, a ausência de investimentos em mudanças e de um trabalho mais direcionado para a escolarização do sujeito que leve em consideração suas subjetividades.

Aqui, na escola, todas as crianças têm laudo. É muito aluno especial. Juntou todo mundo no mesmo turno. O problema é que muitos não acompanham o que os professores ensinam. Eu nem sei se eles têm condições de fazer isso. Quando a coisa aperta, o laudo resolve. Até porque acho que tem uma lei que ampara os alunos. Com o laudo, eles passam direto. Não tem reprovação (RITA - PEDAGOGA)

Pensar na relação estabelecida entre os diagnósticos clínicos e o processo de ensinoaprendizagem dos alunos nos faz recordar Santos (2006), quando argumenta quanto o pensamento moderno produz linhas abissais para dividir a realidade social. $\mathrm{Na}$ escola, os alunos que possuem laudo acabam sendo alocados em um lado invisível do planejamento do professor, situação sustentada na crença de que não podem aprender. Bueno (2008) problematiza a importância de as escolas se aproximarem mais das pesquisas acadêmicas para perceber que a deficiência pode ser socialmente produzida, quando lançamos sobre os alunos um conjunto de prognósticos que evidenciam as suas impossibilidades, e não as suas potências de aprendizagem.

O laudo apresenta-se também como alternativa para os professores na resolução do problema da reprovação, visto que constituíram a ideia de que este instrumento garante legalmente a aprovação, independentemente do conhecimento adquirido pelo aluno. Do mesmo modo, os professores tanto depositam no laudo garantias que legitimem os significados que criam para os alunos com deficiência, quanto buscam respaldo para os estigmas que produzem e reproduzem em suas narrativas. Logo, quando o aluno não tem 


\section{DOI: $10.5902 / 1984686 \times 27314$}

laudo, os professores percebem a fragilidade em seus discursos e precisam recorrer a outros supostos suportes.

Estou com um problemão na minha sala. Não tenho alunos com deficiência esse ano, mas tenho crianças com sérios problemas na alfabetização. Muitos têm dislexia. Tem um que faço de tudo, mas ele não aprende. Ele tem um irmão no $6 . .^{\circ}$ ano e que também não aprendeu. Foi meu aluno. Não sei se é de família. Será que tem algo a ver? Esse menino do 6.ำ ano tem laudo, por isso conseguiu avançar, mas esse, agora, não tem. Não sei o que faço com ele. Se ele, ao menos, tivesse o laudo! (PROFESSORA DO NÚCLEO COMUM).

A professora justificou o que entende como "fracasso" no processo de ensinoaprendizagem, relacionando as dificuldades encontradas à dislexia e, no caso de um dos alunos, em específico, recorreu à constituição biológico-hereditária, para justificar a impossibilidade do aprender - se o aluno e o irmão não aprendem, isso vem de família -, estigma que criou para o aluno e deixa transparecer em sua narrativa. O discurso produzido pela professora também se torna, ele mesmo, mais um obstáculo no ensino. Se, de antemão, se compreende que o aluno não vai conseguir aprender, é visto como perda de tempo para o professor tentar ensinar.

Esse cenário, mais uma vez, revela a importância de as escolas comporem projetos político-pedagógicos que definam ações coletivas, comprometidas com o acesso ao currículo escolar e à formação dos professores (VEIGA, 2009), pois, conforme salientam Bianchetti e Correia (2011), os professores precisam analisar os modos como subjetivam os alunos, porque essas subjetivações implicam a mediação do trabalho pedagógico, 0 acompanhamento dos alunos e a aposta que fazem na aprendizagem desses sujeitos.

Nesse contexto, as narrativas dos professores também fazem emergir os processos de significação dos pressupostos da Educação Especial e dos modos de ser/estar dos estudantes com deficiência na escola. A Educação Especial ainda é vista como uma ação substitutiva à escolarização dos alunos, mesmo que várias produções teóricas (BAPTISTA, 2011; KASSAR, REBELO, 2011; VIEIRA, 2015) e a própria legislação educacional brasileira (BRASIL, 1988; 1996; 2008) acenem para o fato de ela ser configurada, na atualidade, como uma modalidade, ou seja, como um conjunto de conhecimentos e ações pedagógicas que têm o objetivo de dar suporte ao ensino comum para a escolarização dos alunos, distanciando-se, assim, de um caráter substitutivo.

Olha, a gente encontra dificuldade em ensinar os normais. A gente não está dando conta! Aí, o que acontece? Acabamos descartando as crianças com deficiência. Vou ser sincera. É isso que acaba acontecendo! Criamos a ideia de que eles não aprendem e que não é preciso queimar cartucho com eles. Isso faz com que a gente se afaste da aprendizagem deles e quem acaba dando conta deles é a Educação Especial, precisamente, os estagiários. Os 
DOI: $10.5902 / 1984686 \times 27314$

estagiários são realmente os professores deles. Os pais têm os estagiários como referência; não os professores (PROFESSORA do 4.ำ ANO).

Essa leitura sobre a Educação Especial acaba por fazer da sala de aula comum um espaço não capaz de abarcar as necessidades de aprendizagens de sujeitos apoiados pela modalidade de Educação Especial, sendo subjugadas as salas de recursos como um lugar de segregação e o "único" espaço destinado ao desenvolvimento de trabalhos pedagógicos com os estudantes que apresentam comprometimentos físicos, psíquicos, intelectuais e/ou sensoriais. Por isso, Baptista (2011) argumenta a importância de trabalhos colaborativos entre professores do ensino regular e de Educação Especial e uma compreensão mais ampla do atendimento educacional especializado, para que tais serviços não se suprimam nas salas de recursos multifuncionais, mas que sejam realizados em todas as atividades planejadas e desenvolvidas pelos professores, quer no turno regular, quer no contraturno.

Com relação aos alunos, as marcas do biológico, muitas vezes, ganham supremacia sobre a plasticidade cerebral, mesmo tendo Vygotsky (1998) mostrado que o desenvolvimento humano se realiza por meio de trocas entre parceiros sociais e processos de interação e mediação. Nesse sentido, há de se recuperar a ideia de que a aprendizagem é o elemento que possibilita o despertar de processos internos do indivíduo e promove a sua relação com o ambiente sociocultural, reconhecendo, com isso, que a situação do homem como organismo não se desenvolve plenamente sem o suporte de outros indivíduos de sua espécie e sem o acesso à cultura.

Não sei trabalhar com um aluno igual ao Roberto. Ele não fala direito e parece que não entende o que a gente diz. Ele fica na sala de aula e eu toco o barco, porque não sei o que fazer com ele (LILIAN PROFESSORA DE CIÊNCIAS).

A presença do "não" na escolarização dos alunos tem trazido muitas consequências para o desenrolar da Educação Especial na escola de ensino comum. Com relação à escola, tem levado os professores a significá-la como um espaçotempo não capaz de mediar os processos de ensino-aprendizagem de alunos que possuem algum tipo de comprometimento, seja ele físico, psíquico, intelectual e/ou sensorial. Essa categoria (o não) também tem implicado o modo como os docentes se subjetivam professores mediante o desafio de escolarizar estudantes com essas condições. Desenvolvem um sentimento de não-saber-total (VIEIRA, 2015), ou seja, a ideia de que todos os seus conhecimentos e experiências profissionais são insipientes ou frágeis mediante a presença física do aluno com deficiência. Na lógica de Santos (2006), os professores precisam conhecer o que sabem e o que não sabem, 
DOI: $10.5902 / 1984686 \times 27314$

situação denominada pelo autor como douta ignorância, situação que fundamenta a ideia da formação docente como processo permanente. Nessa mesma via, precisam conhecer seus alunos para vê-los como sujeitos de conhecimentos, e não somente sujeitos que, em tudo o que fazem, têm a marca do "não".

\section{Quando as narrativas sobre a deficiência são postas em análise: falando de uma experiência de formação em contexto}

Nos momentos tanto de observação quanto de formação e intervenção em sala de aula, os professores produziam suas narrativas sobre os modos de ser/estar dos alunos apoiados pela Educação Especial. Em várias delas, era possível perceber a inserção da expressão "só" agregada aos modos como os alunos aprendiam ou se envolviam no que Ihes era ensinado. Afinal, o que era o "só"? De início, um monossílabo que parecia incorporar as narrativas dos docentes de maneira não calculada/problemática. Mas, analisado de maneira crítica, simbolizava os modos como os estudantes com deficiência eram significados na escola.

Com o Valentim só alfabetização. É só isso que ele consegue (THALITA PROFESSORA DE EDUCAÇẨO ESPECIAL).

O Adriano precisa do Braille, então, até agora ele só aprendeu alguns pontos, a se locomover melhor na escola, a se alimentar e se comunicar melhor, mas só isso (NÁDIA - PROFESSORA DE EDUCAÇÃO ESPECIAL).

Em um dia destinado à formação continuada, tivemos a oportunidade de problematizar a questão do "só" com os sujeitos envolvidos na pesquisa. Iniciamos esse encontro com a canção: "Preta Pretinha", entoada pelo conjunto "Os Novos Baianos", quando assim dizia: "[...] Só! Só! Somente Só! Assim vou lhe chamar. Assim você vai ser [...]". Essa oportunidade formativa faz recordar os estudos de Jesus (2005), quando destaca que, se desejamos defender escolas inclusivas, precisamos investir incessantemente na formação dos seus educadores. Na compreensão de Santos (2006), precisamos substituir os "nãopodem" por "ainda-não conseguem". Esse último conceito fala de deslocamento e de novas possibilidades de trabalho docente e de aprendizagem.

Muitas vezes, quando eu digo assim 'só isso' é porque eu não fiz outras
tentativas. Eu não percebi outras possibilidades. Eu acho que o 'só'
paralisa, até porque eu tenho que ir além. O 'só' é uma comodidade
também do professor pensar assim. Mas, para isso, eu tenho que me
envolver, eu tenho que me relacionar, eu tenho que estar perto, eu
tenho que dar oportunidade, oferecer coisas diferentes, oferecer coisas
de outras formas. Nós temos vivido o hábito de limitar, apenas por
olhar. Para mudar isso, nós temos que incomodar as pessoas para que 
DOI: $10.5902 / 1984686 \times 27314$

elas possam mudar o olhar a respeito dessa questão, discutir mesmo e não aceitar (CELINA - PROFESSORA DE EDUCAÇÃO ESPECIAL).

Os professores concluíram que o olhar diante do aluno com deficiência era sempre construído com base nas impossibilidades e nas limitações, requisitando mudanças no processo e nas narrativas docentes. Uma docente levantou uma situação que provocou o grupo: “[...], mas se ele é o aluno do 'só' e 'só' aprende determinada coisa, eu passo a ser a professora do 'só' que 'só' ensina isso a ele" (MERCEDES - PROFESSORA). Sentindose provocado, um dos docentes retrucou, dizendo:

[...] fiquei lembrando da última formação quando refletimos que os alunos têm fome pelo conhecimento e que a escola é como se fosse um restaurante que eles procuram para se saciarem. Então, se o aluno é 'só', o conhecimento a ele ofertado é 'só', a professora é 'só', essa escola também é 'só', ou seja, 'só' tem isso para oferecer para eles (MARGARIDA - PROFESSORA).

Esse momento de formação, segundo os estudos de Oliveira (2007), permitia que os professores se autoavaliassem, tendo em vista a pesquisadora sinalizar que, quando eles narram, passam por processos de reconstituição de suas trajetórias e uma análise críticoreflexiva de seus saberes fazeres e de questões que precisam potencializar na prática docente. Os professores concluíram que a ideia do "só" é complexa, tanto para o processo de escolarização dos alunos quanto para os saberes-fazeres dos educadores, pois invisibilizava as tentativas do grupo e abortava qualquer possibilidade de ensinoaprendizagem.

No transcorrer das reflexões, lembramo-nos de um aluno com cegueira que estudava na escola e chegara sem noções de locomoção, alimentando-se por meio de uma mamadeira. Atualmente está em processo significativo de apropriação do Braille, de locomoção, de comunicação, reconhecimento das pessoas e de compreensão do que era realizado em sala de aula. Direcionamo-nos para o professorado e perguntamos: o que é "só" nesse contexto?

\footnotetext{
Eu vejo que você tem razão, porque o Adriano até reconhece a gente. Ele é agarrado com a professora dele que vem trabalhando com ele há mais tempo, mas ele nos reconhece. Ele passa e pergunta: 'Tia, você é como? Você é quem?' E, nessa construção de conhecimentos, ele também precisa aprender a História, a Matemática, as Ciências e a Geografia. Acredito que sim, que ele precisa desses conhecimentos da mesma forma que precisa dos conhecimentos para nos reconhecer, por que senão com que função ele vai aprender e usar o Braille? Então, acredito que ele tem que aprender tudo, no tempo dele, no limite dele, mas que não pode ser privado de nada. $\mathrm{E} o$ aprendizado dele não é 'só', mas a potência dele que temos limitado em nome da deficiência (ELISA - PROFESSORA).
} 
DOI: $10.5902 / 1984686 \times 27314$

Voltamos, mais uma vez, às teorizações de Santos (2006) e questionamos os porquês de lançarmos, para um lado invisível da escola, a aprendizagem e avanços desse aluno. Recorríamos também a Sacristán (2000), quando fala da importância de currículos mais abertos para atender às trajetórias diferenciadas de aprendizagem dos alunos. Com essas teorizações, promovia-se, na lógica de Santos (2007), a tradução/encontro entre um conjunto de fundamentos teóricos que defendem o direito de aprender de todos e os desafios cotidianos que atravessam esse processo.

Falávamos para os professores que precisávamos refletir sobre a aprendizagem desse aluno, porque muitos conhecimentos que ele constituía, por não estarem previstos no currículo escolar e não serem um saber hegemonicamente legitimado, eram subjugados à categoria de senso comum. $O$ aluno chegara à escola com sérias dificuldades de organização de seu pensamento para interagir e se comunicar com seus pares. $O$ discurso dele era um misto de tentativa de comunicação com reproduções de sons ouvidos na rádio e na televisão, durante sua estada em casa. Para ampliarmos as possibilidades de comunicação do aluno, muitas vezes, presenciamos a professora de deficiência visual sinalizando:

Não entendi o que você está falando. Fala para a tia o que você quer! Se você não se expressar direito, não posso te ajudar. Se você não falar direitinho, como vou descobrir que você quer ir ao banheiro? Ouve, a tia está falando. Agora tente fazer o mesmo, dizendo o que você quer (NÁDIA PROFESSORA).

Em outros momentos, a docente dizia: "o que tem a ver essa reprodução do que você ouviu na rádio com a nossa conversa? Lembra que a tia ensinou que a gente tem que pensar no que vai falar, senão o outro não entende?" (NÁDIA - PROFESSORA). Com o passar do tempo, víamos mudanças em sua comunicação. Ele expunha ideias e pensamentos, verbalizava as suas vontades e as suas "pirraças", pedia para ir ao banheiro, e a construção de seus diálogos estava mais compreeensível. Quando não gostava do que era servido na merenda escolar, dizia: "[...] não gosto de sopa. Tem gosto ruim". Nas palavras de Goulart (2006, p. 6), o aluno se constituía como ser pensante e crítico por meio da linguagem, até porque "[...] a linguagem tem papel fundador nesse processo, não só do ponto de vista da construção da singularidade desses sujeitos, mas também da construção das suas marcas de pertencimento a determinado(s) grupo(s)". Como se tratava de um aluno de 9 anos que utilizava a mamadeira, fazer uso de utensílios como prato, garfo e colher simbolizava inserir-se na cultura (VYGOTSKY, 1998). Voltávamos para os 
DOI: $10.5902 / 1984686 \times 27314$

professores e perguntávamos: a produção desse aluno é "só"? O grupo apresentava-se inquieto e incomodado, pois os diálogos colocavam em evidência não somente os alunos, mas a ação dos professores de maneira ampliada.

O contexto possibilitava aos professores refletir sobre a pouca participação dos alunos nas aulas coletivas, pois, muitas vezes, em nome da diferença, negavam o acesso aos conhecimentos que eram trabalhados no contexto da sala de aula comum. Em contrapartida, em nome da igualdade, evidenciavam intervenções coletivas esquecendo particularidades que faziam parte da constituição humana dos estudantes. Esse debate evidenciava as discussões de Santos (2006), ao problematizar que temos o direito de sermos iguais, quando a diferença nos inferioriza, e o direito de sermos diferentes, quando a igualdade nos descaracteriza.

A reflexão sobre o "só" trouxe outras possibilidades de participação para os alunos no currículo escolar. Essa possibilidade de participação diferenciada se evidenciou em um dos momentos vivenciados pelos pesquisadores. Já nos primeiros dias, após a discussão, fomos recebidos pela professora de Educação Especial que escreveu a letra "V" na mão de Valentim - um aluno com síndrome de Down - e pediu que ele nos apresentasse: "[...] mostra, Valentim, a letrinha do seu nome. Fala que letra é essa. Ele já sabe que o ' $V$ ' é a letra do nome dele. Ele conhece as vogais, os números e as cores" (THALITA - PROFESSORA DE EDUCAÇÃO ESPECIAL).

Os momentos de formação continuada ajudavam os professores a refletir a respeito do que narravam sobre os alunos, mas também indicavam a necessidade de assumir a apropriação do conhecimento como função social da escola. Os docentes podiam refletir: para que serve o conhecimento? A quem ele serve? Com quais propósitos são explorados? Por que alguns conhecimentos são considerados relevantes enquanto outros são descartados?

O discurso da normalidade também foi debatido durante a formação, pois, compreendendo que o processo de ensino-aprendizagem se dá no coletivo, mas que diz muito do desenvolvimento subjetivo do aluno, não era possível conceber a ideia de um padrão de "normalidade" de aquisição do conhecimento a ser atingido por todos de maneira uniforme. As narrativas dos professores revelaram que havia uma preocupação em padronizar saberes e comportamentos, em tornar "normal":

Tem aluno que dá para ser trabalhado. Tem menino aqui que é quase normal. A gente consegue fazer alguma coisa com ele, mas tem outros que não dá. 'Tá muito distante do normal. É mais comprometido. A menina não fala, não anda, não escreve. Demora uns dez minutos para responder o que a gente pergunta. Como envolver essa menina no currículo? Eu não sei nem por onde começar? (LILIAN - PROFESSORA DE CIÊNCIAS). 
DOI: $10.5902 / 1984686 \times 27314$

Para tanto, discutimos quanto o pensamento moderno produz a monocultura das diferenças, que leva todo sujeito considerado diferente a ser visto como residual e desigual. Como diz Santos (2006, p. 281), a razão indolente cria "[...] os excluídos foucaultianos, o 'eu' e o 'outro', simétricos numa partilha que rejeita ou interdita tudo o que cai no lado errado da partilha", tomando a primazia da padronização em detrimento do reconhecimento das diferenças como a base de sustentação dos processos de desigualdade. Esse grupo passa a ser subjetivado sob a ótica da periculosidade, da ineficiência, tendo seus potenciais negados e suas necessidades de conhecer negligenciadas.

Em contrapartida, com os processos formativos, novas possibilidades de subjetivação eram construídas sobre os alunos, pois a problematização produzida com os docentes trazia outras narrativas e a tentativa de contemplar as necessidades de aprendizagem dos alunos em sala de aula:

A gente vem desde criança com a mente formada que a pessoa especial é muito limitada. Ah! Eu pensava assim: Fulano, que tem tal deficiência, não vai aprender muita coisa. Está na escola só por estar. Eu não pensava que ele estava realmente se expandindo. Quando a gente achava que a criança aprendia tal coisa, para a gente era só aquilo que ele podia aprender. Hoje não. Hoje já é aprende isso e pode está aprendendo mais. Glorinha aprende porque ela também tem capacidade. Ela tem uma deficiência, mas ela também pode aprender. Todos têm capacidade (JANAÍNA PROFESSORA).

O grupo estava inquieto e movido a pensar na necessidade de reorganizar os trabalhos da escola para constituir propostas com os alunos. As narrativas dos profissionais da escola começavam a ser encharcadas de preocupações sobre o sentido que a aprendizagem exercia na formação de cada um dos alunos. Como diz Cury (2008), a educação é um direito inalienável, cabendo ao Estado e à família criar condições para que os estudantes o usufruam, conhecimento que talvez os processos de formação vividos na pesquisa tenham deixado como legado para a escola.

\section{Considerações finais}

O estudo confirmou que o modo como os professores significam os alunos, por meio de suas narrativas, vêm contribuindo para a exclusão desses sujeitos e tornando-se obstáculo nos processos de ensino-aprendizagem, em que o olhar humano, afetado pelos princípios da normalidade, busca homogeneizar e descartar todo ser vivente rotulado como diferente. $\mathrm{Na}$ escola, esses processos são 
naturalizados e o aluno com deficiência permanece excluído dos planejamentos, invisibilidade no currículo e negligenciado nas práticas educativas.

\section{Referências}

BAPTISTA, C. R. Ação Pedagógica e educação especial: a sala de recursos como prioridade na oferta de atendimentos especializados. Revista Brasileira de Educação Especial. v. 17, p. 59-76, maio/ago. 2011.

BARBIER, Renné. A pesquisa-ação. Tradução de Lucie Didio. Brasília: Líber Livro Editora, 2004.

BIANCHETTI, Lucídio; CORREA, José Alberto. In/exclusão no trabalho e na educação: aspectos mitológicos, históricos e conceituais. Campinas: Papirus, 2011. BRASIL, Ministério da Educação. Política pública de educação especial na perspectiva da educação inclusiva, 2008. Disponível em: $<$ <ttp://portal.mec.gov.br/arquivos/pdf/politicaeducespecial.pdf>. Acesso em: 10 mar. 2016.

BRASIL. Constituição (1988). Constituição [da] República Federativa do Brasil. Brasília: Senado Federal, 1988.

BRASIL. Lei n 9.394, de 20 de dezembro de 1996. Estabelece as diretrizes e bases da educação nacional. Diário Oficial [da] República Federativa do Brasil, Brasília, 23 de dez. 1996. Seção 1.

BUENO, José Geraldo Silveira. As políticas de inclusão escolar: uma perspectiva de educação especial? In: BUENO, José Geraldo Silveira; MENDES, Giovana Mendonça Lunardi; SANTOS, Roseli Albino dos (Org.). Deficiência e escolarização: novas perspectivas de análise. Araraquara, SP: Junqueira \& Marin, 2008. p. 43-63.

CURY, Carlos Roberto Jamil. A educação básica como direito. Revista Cadernos de Pesquisa, São Paulo, v. 38, n. 134, maio/ago., p. 293-303, 2008.

GOULART, Cecília. Letramento e modos de ser letrado: discutindo a base teóricometodológica de um estudo. Revista Brasileira de Educação, Rio de Janeiro, v.11, n. 33, set./dez. 2006.

JESUS, Denise Meyrelles de. Formação continuada: construindo um diálogo entre teoria, prática, pesquisa e educação inclusiva. In: JESUS, Denise Meyrelles de; BAPTISTA, Claudio Roberto; VICTOR, Sonia Lopes (Org.). Pesquisa e educação especial: mapeando produções. Vitória: Edufes, 2005. p. 203-218. 
DOI: $10.5902 / 1984686 \times 27314$

KASSAR, Mônica de Carvalho Magalhães; REBELO, Andressa Santos. O "especial" na educação, o atendimento especializado e a educação especial. In: SEMINÁRIO NACIONAL DE PESQUISA EM EDUCAÇÃO ESPECIAL. PRÁTICA PEDAGÓGICA NA EDUCAÇÃO ESPECIAL: MULTIPLICIDADE DO ATENDIMENTO EDUCACIONAL ESPECIALIZADO, 6., 2011, Nova Almeida. 2011. Anais... Nova Almeida: Snpee, 2011. v. 1, p. 1-17, 1 CD-ROM.

OLIVEIRA, Ivone Martins de. A narrativa como possibilidade de abordagem dos conhecimentos produzidos pelo professor sobre sua prática. In: JESUS, Denise Meyrelles de et al. (Org.). Inclusão, práticas pedagógicas e trajetórias de pesquisa. Porto Alegre: Mediação/Prefeitura Municipal de Vitória/CDV/FACITEC, 2007. p. 251260.

SACRISTÁN, José Gimeno. O currículo: uma reflexão sobre a prática. 3. ed. Tradução de Ernani F. da F. Rosa. Porto Alegre: Artmed. 2000.

SANTOS, Boaventura de Sousa. A filosofia à venda, a douta ignorância e a aposta de Pascal. Revista crítica de ciências sociais, Coimbra, Portugal, n. 80, p. 11-43, mar. 2008.

SANTOS, Boaventura de Sousa. A gramática do tempo: para uma nova cultura política. São Paulo: Editora Cortez, 2006.

SANTOS, Boaventura de Sousa. Renovar a teoria crítica e reinventar a emancipação social. São Paulo: Boitempo, 2007.

VEIGA, IIma Passos Alencastro. Projeto político-pedagógico da escola: uma construção coletiva. In: VEIGA, IIma Passos Alencastro et al. Projeto políticopedagógico da escola: uma construção possível. Campinas: Papirus, 2009. p. 11- 35. VIEIRA, Alexandro Braga. Táticas e estratégias constituídas por professores para articulação do currículo escolar e o atendimento educacional especializado. 2015. Relatório de Pós-Doutorado (Pós-Doutorado em Educação) - Programa de PósGraduação em Educação, Universidade Federal do Espírito Santo, Vitória, 2015. VYGOTSKY, Lev Semenovich. A formação social da mente: o desenvolvimento dos processos psicológicos superiores, São Paulo: Martins Fontes, 1998.

\section{Correspondência}

Alexandro Braga Vieira- Universidade Federal do Espírito Santo, Av. Fernando Ferrari, 514 - Goiabeiras. CEP: 29075-910 Vitória, Espirito Santo, Brasil. 
DOI: $10.5902 / 1984686 \times 27314$

\section{(c) (i) (8)}

Th is work is licensed under a Creative Commons Attribution-NonCommercial 4.0 International (CC BY-NC 4.0) 